\title{
Characteristics and Psychiatric Symptoms of Internet Gaming Disorder among Adults Using Self-Reported DSM-5 Criteria
}

\author{
Na Ri Kim¹, Samuel Suk-Hyun Hwang², Jung-Seok Choi ${ }^{3}$, Dai-Jin Kim², Zsolt Demetrovics ${ }^{5}$, Orsolya Király ${ }^{5}$, \\ Katalin Nagygyörgy ${ }^{5}$, Mark. D. Griffiths ${ }^{6}$, So Yeon Hyun ${ }^{7}$, Hyun Chul Youn ${ }^{8}$, and Sam-Wook Choi',10凶 \\ 'Laboratory of Addiction Policy, Seoul St. Mary's Hospital, The Catholic University of Korea, Seoul, Republic of Korea \\ 2Department of Psychology, Chonnam National University, Gwangju, Republic of Korea \\ ${ }^{3}$ Department of Psychiatry, SMG-SNU Boramae Medical Center, Seoul, Republic of Korea \\ ${ }^{4}$ Seoul St. Mary's Hospital, College of Medicine, The Catholic University of Korea, Seoul, Republic of Korea \\ ${ }^{5}$ Institute of Psychology, Eötvös Loránd University, Budapest, Hungary \\ ${ }^{6}$ Nottingham Trent University, Psychology Division, Nottingham, United Kingdom \\ 'Eulji Addiction Institute, Gangnam Eulji Hospital, Eulji University, Seoul, Republic of Korea \\ ${ }^{8}$ Chungmugong Leadership Center, Naval Education and Training Command, Republic of Korea Navy, Changwon, Republic of Korea \\ ${ }^{9}$ Korea Institute on Behavioral Addictions, Easy Brain Clinic, Seoul, Republic of Korea \\ ${ }^{10} \mathrm{Health}$ Care \& Information Research Institute, Namseoul University, Cheonan, Republic of Korea
}

Objective The Section III of the Diagnostic and Statistical Manual of Mental Disorders, Fifth Edition (DSM-5) proposed nine diagnostic criteria and five cut-point criteria for Internet Gaming Disorder (IGD). We aimed to examine the efficacy of such criteria.

Methods Adults ( $\mathrm{n}=3041$, men: 1824, women: 1217) who engaged in internet gaming within last 6 months completed a self-report online survey using the suggested wordings of the criteria in DSM-5. Major characteristics, gaming behavior, and psychiatric symptoms of IGD were analyzed using ANOVA, chi-square, and correlation analyses.

Results The sociodemographic variables were not statistically significant between the healthy controls and the risk group. Among the participants, 419 (13.8\%) were identified and labeled as the IGD risk group. The IGD risk group scored significantly higher on all motivation subscales $(\mathrm{p}<0.001)$. The IGD risk group showed significantly higher scores than healthy controls in all nine psychiatric symptom dimensions, i.e., somatization, obsession-compulsion, interpersonal sensitivity, depression, anxiety, hostility, phobic anxiety, paranoid ideation, and psychoticism $(\mathrm{p}<0.001)$.

Conclusion The IGD risk group showed differential psychopathological manifestations according to DSM-5 IGD diagnostic criteria. Further studies are needed to evaluate the reliability and validity of the specific criteria, especially for developing screening instruments.

Psychiatry Investig 2016;13(1):58-66

Key Words Internet gaming disorder, DSM-5, Psychiatric symptoms.

\section{INTRODUCTION}

In 2013, the Diagnostic and Statistical Manual of Mental Disorders, Fifth Edition (DSM-5) of the American Psychiatric Association included Internet Gaming Disorder (IGD) in Section III, thus warranting more research before it might

\footnotetext{
Received: January 29, 2015 Revised: April 23, 2015

Accepted: May 15, 2015 Available online: October 27, 2015

$\triangle$ Correspondence: Sam-Wook Choi, MD, PhD

Korea Institute on Behavioral Addictions, Easy Brain Clinic, F2, Seojeon B/D, 173 Saimdang-ro, Seocho-gu, Seoul 06626, Republic of Korea

Tel: +82-2-583-9080, Fax: +82-2-583-9082, E-mail: peaceinu@hanmail.net

(a) This is an Open Access article distributed under the terms of the Creative Commons Attribution Non-Commercial License (http://creativecommons.org/licenses/bync/3.0) which permits unrestricted non-commercial use, distribution, and reproduction in any medium, provided the original work is properly cited.
}

gain official recognition.

According to recent studies, ${ }^{2}$ researchers discussed the addition of non-substance-related addictive disorders to DSM-5. IGD was added based upon reviews, a voting process, about 250 research publications, and from the growing medical risk of IGD.

There are several difficulties in properly diagnosing and treating IGD. While the number of publications related to 'internet game addiction, ${ }^{3-5}$ 'internet game dependency, ${ }^{6-8}$ 'IGD, 2,9-14 and other names ${ }^{11,14}$ has been steadily on the rise, the consensus on the standards of IGD has not yet been reached. Therefore, concept of IGD needs to be clarified further and standardized criteria for research has to be developed.

Research on IGD prevalence ${ }^{7,15-20}$ has shown limited con- 
sistency. Depending on the criteria used, prevalence rates vary from less than $1 \%^{15-17}$ to approximately $10 \%^{2,18-20}$ In addition, many reports focus on children, adolescents, and young adults, resulting in a general lack of adult-targeted research.

To address the efficacy of the IGD classification of DSM$5^{12}$ and the limited consensus on the proposed criteria, ${ }^{1}$ the appropriateness of the proposed diagnostic criteria of DSM5 should be examined systematically. To this end, studies to develop standardized and refined criteria and integrated assessment methods are necessary. ${ }^{2}$

This study aimed to characterize different psychiatric symptoms of IGD, including internet gaming experience, motivation and impulsivity by comparing the risk group and healthy control group applying DSM-5 diagnostic criteria as an extension of an international collaborative research effort involving eight countries (including for example, Korea, Hungary, and the United Kingdom). Secondly, we also aimed to estimate IGD prevalence among adults in Korea.

\section{METHODS}

\section{Cross-cultural data collection and questionnaire translation}

The same online questionnaire was used to collect data from gamers speaking Hungarian, English, Italian, Norwegian, Slovenian, French, Romanian, and Korean. For the Korean survey, however, we included additional questions pertaining to the DSM-5 diagnostic criteria in order to derive the estimation of adult IGD Characteristics.

Translations of the survey were carried out by research colleagues from the respective collaborating countries and back translated by another expert. The back-translations of the initial Korean version of the survey were compared with the original English version and differences were discussed until a consensus was reached by a graduate-level bilingual. The final version was shown to a group of gamers who gave their opinions regarding the clarity and comprehension of the items.

\section{Subjects}

A total of 3041 adults (20 to 49 years of age) who had engaged in Internet gaming within 6 months from the start of the study participated (data collected from March 17-28, 2014). The data collection was carried out by Korea's Most Prestigious Market and Opinion Research Firm (KMPMORF) through the Computer Aided Web Interview (CAWI) method. The informed consent was obtained from participants prior to their inclusion in the survey. This study was approved by the Institutional Review Board of the Eötvös Loránd University in Hungary and Eulji University in Korea, respectively. The sample was not nationally representative.
The survey was completed through random in Korea. Total sample size was 3041 (Men $n=1824$, Women $n=1217)$.

\section{Measurements}

\section{Sociodemographic data}

Major sociodemographic characteristics such as gender, age, marital status, educational level, and current work status were obtained.

\section{Gaming-related questions}

Gaming-related questions such as online game type preference and weekly playing time were given. Based on previous findings, ${ }^{21}$ three popular game types [first-person shooter (FPS), role playing games (RPGs), and real time strategy (RTS) games] and an 'other' categories were offered to identify main game type preference.

Categories for weekly playing time were the following: less than 1 hour a day (less than seven hours weekly), 1-2 hours per day (7-14 hours weekly), 2-4 hours per day (15-28 hours weekly), 4-6 hours per day (29-42 hours weekly), and more than 6 hours per day (more than 42 hours weekly).

The Motives for Online Gaming Questionnaire ${ }^{22}$ (MOGQ)

MOGQ is a 27-item self-reported questionnaire assessing the full range of motives for online gaming, including escape (4 items), coping (4 items), fantasy (4 items), skill development (4 items), recreation (3 items), competition (4 items), and social ( 4 items). The instrument uses a 5-point Likert scale from "never" to "almost always/always," with higher scores indicating higher frequency of the respective motivational dimension. Internal consistencies were reported for all seven dimensions, ranging from 0.79 to $0.90^{22}$ and the present sample as well (Cronbach's alpha $=0.912$ ).

\section{The diagnostic criteria of IGD in DSM-5}

In DSM-5, IGD is identified in section III as a condition warranting more clinical research and experience before it might be considered for inclusion in the main book as a formal disorder. The diagnostic criteria of IGD in the DSM-5 are composed of 9 items: preoccupation, withdrawal, tolerance, unsuccessful attempts to control, loss of other interests, continued excessive use despite psychosocial problems, deceiving regarding online gaming, escape, and functional impairment1. Meeting five or more DSM- 5 criteria of IGD proved to be the best cut-off point in a previous study. ${ }^{11}$ The suggested wordings of the DSM- 5 criteria was applied in this computer aided web interview using a "yes" or "no" response form. According to these DSM- 5 criteria, we divided the participants into risk group and healthy controls. We used the 
term 'risk group', not 'patient group', because we did not confirm the diagnosis with clinical interview.

\section{BSI $^{23-27}$}

To assess self-reported clinically relevant psychological symptoms and distress, the present study used the Brief Symptom Inventory (BSI). ${ }^{24}$ This 53-item questionnaire uses a 5-point Likert scale (from "not at all" to "extremely") and comprises nine symptom dimensions: somatization (7 items), obsession-compulsion (6 items), interpersonal sensitivity (4 items), depression (6 items), anxiety (6 items), hostility (5 items), phobic anxiety (5 items), paranoid ideation (5 items), and psychoticism (5 items). Good reliability and validity have been found across various samples ${ }^{23,24,28}$ and the present sample as well (Cronbach's alpha=0.982).

BIS $^{29}$

Impulsivity was measured by the 21 -item revised version of the original Barratt Impulsiveness Scale (BIS). ${ }^{29}$ The 21 items comprise three factors [self-control ( 9 items), impulsive behavior (5 items), and impatience ( 7 items)] and the factors are rated on a 4-point Likert scale (from "rarely/never" to "almost always/always"). The Cronbach's alpha of present sample was 0.769 .

\section{Statistical analysis}

All analyses were conducted with SPSS software version 18.0 (SPSS, IBM corp., NY, USA). A p level lower than 0.05 was

Table 1. Comparison of sociodemographic characteristics between healthy controls and the risk group

\begin{tabular}{|c|c|c|c|c|c|}
\hline \multirow{2}{*}{$\begin{array}{c}\text { Variables } \\
\text { (\% within group) }\end{array}$} & \multirow{2}{*}{$\begin{array}{c}\text { Total } \\
(\mathrm{N}=3041)\end{array}$} & \multicolumn{2}{|c|}{ DSM-5 diagnosis } & \multirow[b]{2}{*}{$\chi^{2}$} & \multirow[b]{2}{*}{$\mathrm{p}$} \\
\hline & & $\begin{array}{l}\text { Healthy control group } \\
\qquad(\mathrm{N}=2622)\end{array}$ & $\begin{array}{l}\text { Risk group } \\
(\mathrm{N}=419)\end{array}$ & & \\
\hline \multicolumn{6}{|l|}{ Sex } \\
\hline Male & $1824(60.0)$ & $1586(60.5)$ & $238(56.8)$ & 2.045 & 0.153 \\
\hline Female & $1217(40.0)$ & $1036(39.5)$ & $181(43.2)$ & & \\
\hline \multicolumn{6}{|l|}{ Age (years) } \\
\hline $20-29$ & $1221(40.2)$ & $1061(40.5)$ & $160(38.2)$ & 0.873 & 0.646 \\
\hline $30-39$ & $1215(40.0)$ & $1040(39.7)$ & $175(41.8)$ & & \\
\hline $40-49$ & $605(19.8)$ & $521(19.9)$ & $84(20.0)$ & & \\
\hline \multicolumn{6}{|l|}{ Marital status } \\
\hline Single & $1659(54.6)$ & $1435(54.7)$ & $224(53.5)$ & 1.783 & 0.619 \\
\hline Married & $1325(43.6)$ & $1139(43.4)$ & $186(44.4)$ & & \\
\hline Divorced/Widowed & $57(1.9)$ & $42(1.8)$ & $9(2.1)$ & & \\
\hline \multicolumn{6}{|l|}{ Educational status } \\
\hline$\leq$ High school & $487(16.0)$ & $421(16.1)$ & $66(15.8)$ & & \\
\hline$\leq$ College & $1760(57.9)$ & $1513(57.7)$ & 247 (58.9) & 1.019 & 0.797 \\
\hline$\leq$ University & $354(11.6)$ & $311(11.9)$ & $43(10.3)$ & & \\
\hline Graduate school $\leq$ & $440(14.5)$ & $377(14.4)$ & $63(15.0)$ & & \\
\hline \multicolumn{6}{|l|}{ Employment status } \\
\hline Full-time & $1630(53.6)$ & $1400(53.4)$ & $230(54.9)$ & & \\
\hline Half-time & $245(8.1)$ & $216(8.2)$ & $29(6.9)$ & 1.022 & 0.906 \\
\hline Part-time & $78(2.6)$ & $68(2.6)$ & $10(2.4)$ & & \\
\hline Temporary & $106(3.5)$ & $92(3.5)$ & $14(3.3)$ & & \\
\hline Unknown & $982(32.3)$ & $846(32.3)$ & $136(32.5)$ & & \\
\hline \multicolumn{6}{|l|}{ Monthly pay (10,000 Won) } \\
\hline$\leq 200$ & $513(16.9)$ & $432(16.5)$ & $81(19.3)$ & 3.230 & 0.358 \\
\hline $201 \leq 400$ & $1345(44.2)$ & $1157(44.1)$ & $188(44.9)$ & & \\
\hline $401 \leq 600$ & $802(26.4)$ & $703(26.8)$ & $99(23.6)$ & & \\
\hline $600<$ & $381(12.5)$ & $330(12.6)$ & $51(12.2)$ & & \\
\hline
\end{tabular}

DSM-5: Diagnostic and Statistical Manual of Mental Disorders, Fifth Edition 
considered significant. Prevalence was derived based on the percentage of participants giving positive responses to five or more DSM-5 criteria of IGD as suggested by previous clinical research. ${ }^{1,2,11}$

Further, we analyzed the differences between the healthy control and risk group in order to investigate the sociodemo- graphic characteristics, and psychiatric symptoms associated with internet game overuse.

The descriptive data were expressed as frequency and percentage or mean and standard deviation. Chi-square analyses and analysis of variance (ANOVA) were used to test the difference of distribution, and the mean differences between the

Table 2. Weekly online game playtime

\begin{tabular}{|c|c|c|c|c|c|}
\hline \multirow{2}{*}{$\begin{array}{l}\text { Playtime (per day) } \\
\text { (\% within group) }\end{array}$} & \multirow{2}{*}{$\begin{array}{c}\text { Total } \\
(\mathrm{N}=3041)\end{array}$} & \multicolumn{2}{|c|}{ DSM-5 diagnosis } & \multirow[b]{2}{*}{$x^{2}$} & \multirow[b]{2}{*}{$\mathrm{p}$} \\
\hline & & $\begin{array}{l}\text { Healthy control group } \\
\qquad(\mathrm{N}=2622)\end{array}$ & $\begin{array}{l}\text { Risk group } \\
(\mathrm{N}=419)\end{array}$ & & \\
\hline$<1$ hour & $1178(38.7)$ & $1083(41.3)$ & $95(22.7)$ & 106.169 & $<0.001$ \\
\hline 1-2 hours & $1015(33.4)$ & $886(33.8)$ & $129(30.8)$ & & \\
\hline $2-4$ hours & $619(20.4)$ & $488(18.6)$ & $131(31.3)$ & & \\
\hline 4-6 hours & $150(4.9)$ & $114(4.3)$ & $36(8.6)$ & & \\
\hline 6 hours $<$ & $79(2.6)$ & $51(1.9)$ & $28(6.7)$ & & \\
\hline
\end{tabular}

DSM-5: Diagnostic and Statistical Manual of Mental Disorders, Fifth Edition

Table 3. Online game typology

\begin{tabular}{|c|c|c|c|c|c|}
\hline \multirow{2}{*}{$\begin{array}{c}\text { Variables } \\
\text { (\% within group) }\end{array}$} & \multirow{2}{*}{$\begin{array}{c}\text { Total } \\
(\mathrm{N}=3041)\end{array}$} & \multicolumn{2}{|c|}{ DSM-5 diagnosis } & \multirow[b]{2}{*}{$\chi^{2}$} & \multirow[b]{2}{*}{$\mathrm{p}$} \\
\hline & & $\begin{array}{l}\text { Healthy control group } \\
\qquad(\mathrm{N}=2622)\end{array}$ & $\begin{array}{l}\text { Risk group } \\
(\mathrm{N}=419)\end{array}$ & & \\
\hline \multicolumn{6}{|l|}{ RPG } \\
\hline Never & $1167(38.4)$ & $1079(41.2)$ & $88(21.0)$ & 79.820 & $<0.001$ \\
\hline Than once a month & $465(15.3)$ & $408(15.6)$ & $57(13.6)$ & & \\
\hline At least monthly & $435(14.3)$ & $360(13.7)$ & $75(17.9)$ & & \\
\hline At least weekly & $697(22.9)$ & $554(21.1)$ & $143(34.1)$ & & \\
\hline Daily & $227(9.1)$ & $221(8.4)$ & $56(13.4)$ & & \\
\hline \multicolumn{6}{|l|}{ FPS } \\
\hline Never & $1545(50.8)$ & $1425(54.3)$ & $120(28.6)$ & 131.090 & $<0.001$ \\
\hline Than once a month & $521(17.1)$ & $451(17.2)$ & $70(16.7)$ & & \\
\hline At least monthly & $429(14.1)$ & $342(13.0)$ & $87(20.8)$ & & \\
\hline At least weekly & $441(14.5)$ & $327(12.5)$ & $114(27.2)$ & & \\
\hline Daily & $105(3.5)$ & $77(2.9)$ & $28(6.7)$ & & \\
\hline \multicolumn{6}{|l|}{ RTS } \\
\hline Never & $1403(46.1)$ & $1307(49.8)$ & $96(22.9)$ & 179.220 & $<0.001$ \\
\hline Than once a month & $524(17.2)$ & $471(18.0)$ & $53(12.6)$ & & \\
\hline At least monthly & $452(14.9)$ & $350(13.3)$ & $102(24.3)$ & & \\
\hline At least weekly & $519(17.1)$ & $400(15.3)$ & $119(28.4)$ & & \\
\hline Daily & $143(4.7)$ & $94(3.6)$ & $49(11.7)$ & & \\
\hline \multicolumn{6}{|l|}{ Other online games } \\
\hline Never & $553(18.2)$ & $56(19.2)$ & $50(11.9)$ & 16.182 & 0.003 \\
\hline Than once a month & 445 (14.6) & $389(14.8)$ & $56(13.4)$ & & \\
\hline At least monthly & $577(19.0)$ & $496(18.9)$ & $81(19.3)$ & & \\
\hline At least weekly & $922(30.3)$ & $776(29.6)$ & $146(34.8)$ & & \\
\hline Daily & $544(17.9)$ & $458(17.5)$ & $86(20.5)$ & & \\
\hline
\end{tabular}

DSM-5: Diagnostic and Statistical Manual of Mental Disorders, Fifth Edition, RPG: role playing game, FPS: first-person shooter, RTS: real time strategy 
healthy control and risk group. Lastly, to investigate the relationship among variables in the diagnosis of IGD, the Pearson's correlation coefficient was used.

\section{RESULTS}

\section{Sociodemographic characteristics}

Among the 3041 participants, 419 subjects (13.8\%) were identified and labeled as the IGD risk group and 2622 subjects $(86.2 \%)$ were labeled as healthy controls (Table 1$)$. The frequency of men $(60.0 \%)$ was higher than that of women (40.0\%), and most individuals were in their twenties to thirties, accounting for $80.2 \%$ of participants. Most were single (54.6\%), followed by married (43.6\%) individuals. Most had not graduated college (57.9\%) and held a full-time job (56.3\%). In-come levels show that the highest proportion (44.2\%) of people earned monthly income between 2,000,000 and 4,000,000 won (approximately 1800-3600 USD).

\section{Online-game playing time}

The online-game playing time is shown in Table 2. Most individuals played less than 1 hour a day (less than 7 hours weekly) (38.7\%), followed by 1-2 hours per day (7-14 hours weekly) (33.4\%), 2-4 hours per day (15-28 hours weekly) (20.4\%), 4-6 hours per day (29-42 hours weekly) (4.9\%), and more than 6 hours per day (more than 42 hours weekly) (2.6\%). The risk group subjects tended to belong significantly more to the categories with a relatively high weekly online game playtime than healthy controls $(\mathrm{p}<0.001)$.

\section{Online-game type}

On average, $22.9 \%$ of subjects played RPGs at least once a week, and $9.1 \%$ played them every day (Table 3 ). The frequency of RPG use in the risk group was on average about 1.6 times higher than for healthy controls $(p<0.001)$. In the case of FPS games, $14.5 \%$ played at least once a week on average, and $3.5 \%$ played every day. The FPS games were played by the risk group approximately 2 times more frequently than by healthy controls $(\mathrm{p}<0.001)$. For RTS games, $17.1 \%$ of subjects played at least once a week on average, and $4.7 \%$ played every day. The frequency of RTS game play in the risk group was on average about 2 times higher than in the case of healthy controls $(\mathrm{p}<0.001)$. The frequency of 'other' online games (sports, puzzle, etc.) was about 1.2 times higher in the risk

Table 4. Motives for online gaming questionnaire

\begin{tabular}{|c|c|c|c|c|}
\hline \multirow{2}{*}{ Factors } & \multicolumn{2}{|c|}{ DSM-5 diagnosis } & \multirow{2}{*}{$\mathrm{F}$} & \multirow{2}{*}{$\mathrm{p}$} \\
\hline & Healthy control group $(\mathrm{N}=2622)$ & Risk group $(\mathrm{N}=419)$ & & \\
\hline Escape & $9.03 \pm 3.61$ & $13.33 \pm 3.29$ & 526.25 & $<0.001$ \\
\hline Coping & $10.32 \pm 3.15$ & $13.28 \pm 3.04$ & 339.63 & $<0.001$ \\
\hline Fantasy & $7.45 \pm 3.63$ & $12.07 \pm 3.92$ & 577.09 & $<0.001$ \\
\hline Skill development & $8.30 \pm 3.61$ & $11.66 \pm 3.64$ & 317.88 & $<0.001$ \\
\hline Recreation & $10.37 \pm 2.71$ & $11.16 \pm 2.40$ & 38.52 & $<0.001$ \\
\hline Competition & $8.83 \pm 3.76$ & $12.51 \pm 3.89$ & 362.69 & $<0.001$ \\
\hline Social & $8.20 \pm 3.73$ & $11.63 \pm 3.86$ & 325.63 & $<0.001$ \\
\hline
\end{tabular}

DSM-5: Diagnostic and Statistical Manual of Mental Disorders, Fifth Edition

Table 5. Correlation between online game typology and MOGQ $(\mathrm{N}=3041)$

\begin{tabular}{|c|c|c|c|c|c|c|c|}
\hline Factors & Escape & Coping & Fantasy & Skill development & Recreation & Competition & Social \\
\hline \multicolumn{8}{|c|}{ Risk group $(\mathrm{N}=419)$} \\
\hline RPG & $0.293^{\dagger}$ & $0.339^{\dagger}$ & $0.408^{\dagger}$ & $0.350^{\dagger}$ & $0.211^{\dagger}$ & $0.331^{\dagger}$ & $0.417^{\dagger}$ \\
\hline FPS & $0.209^{\dagger}$ & $0.285^{\dagger}$ & $0.350^{\dagger}$ & $0.397^{\dagger}$ & $0.127^{\dagger}$ & $0.341^{\dagger}$ & $0.387^{\dagger}$ \\
\hline RTS & $0.208^{\dagger}$ & $0.338^{\dagger}$ & $0.391^{\dagger}$ & $0.429^{\dagger}$ & $0.192^{\dagger}$ & $0.449^{\dagger}$ & $0.384^{\dagger}$ \\
\hline Others & $0.180^{\dagger}$ & $0.180^{\dagger}$ & $0.140^{\dagger}$ & $0.234^{\dagger}$ & $0.145^{\dagger}$ & $0.175^{\dagger}$ & $0.104^{*}$ \\
\hline \multicolumn{8}{|c|}{ Healthy control group $(\mathrm{N}=2622)$} \\
\hline RPG & $0.221^{\dagger}$ & $0.291^{\dagger}$ & $0.299^{\dagger}$ & $0.271^{\dagger}$ & $0.285^{\dagger}$ & $0.161^{\dagger}$ & $0.387^{\dagger}$ \\
\hline FPS & $0.229^{\dagger}$ & $0.267^{\dagger}$ & $0.304^{\dagger}$ & $0.298^{\dagger}$ & $0.146^{\dagger}$ & $0.290^{\dagger}$ & $0.302^{\dagger}$ \\
\hline RTS & $0.239^{\dagger}$ & $0.293^{\dagger}$ & $0.297^{\dagger}$ & $0.334^{\dagger}$ & $0.206^{\dagger}$ & $0.318^{\dagger}$ & $0.370^{\dagger}$ \\
\hline Others & $0.118^{\dagger}$ & $0.097^{\dagger}$ & $0.058^{\dagger}$ & $0.112^{\dagger}$ & $0.051^{\dagger}$ & $0.129^{\dagger}$ & -0.010 \\
\hline
\end{tabular}


group as compared with healthy controls $(\mathrm{p}<0.003)$. On average $30.3 \%$ played 'other' games at least once a week, and $17.9 \%$ played them every day.

\section{The motives for online gaming}

Using the MOGQ to assess the motives for online gaming, the risk group used online gaming to escape from reality or specific issues more than the healthy controls (13.33 vs. 9.03 , $\mathrm{p}<0.001$, respectively) (Table 4 ). Also, the risk group showed higher score in the use of online gaming as a coping mechanism compared to the healthy control group (13.28 vs. 10.32, $\mathrm{p}<0.001$, respectively). Likewise, the risk group scored significantly higher on all other motivation subscales (12.07/7.45, $11.66 / 8.30,0.16 / 10.3711,12.51 / 8.83$, and $11.63 / 8.20$ for fantasy, skill development, recreation, competition, and social, respectively, $\mathrm{p}<0.001)$.

\section{Correlation between online game types and the motives for online game}

Table 5 shows the correlations between online game type by subjects and the motives for online game play (MOGQ). The seven motivation factors for online gaming were positively correlated with the game type choice for individuals in the risk group. The range of correlations between game type and MOGQ was 0.104-0.449.

The use of RPGs by subjects of the IGD risk group was strongly correlated with fantasy $(r=0.408, p<0.01)$ and social $(\mathrm{r}=0.417, \mathrm{p}<0.01)$ factors. FPSs users in the IGD risk group were significantly correlated with skill development ( $r=0.397$, $\mathrm{p}<0.01$ ), and RTS game users in the IGD risk group were significantly correlated with both skill development ( $r=0.429$, $\mathrm{p}<0.01)$ and competition $(\mathrm{r}=0.449, \mathrm{p}<0.01)$.

The use of RPGs and RTS games by healthy controls were significantly correlated with social factors (RPGs: $r=0.387$, $\mathrm{p}<0.01$; RTS: $\mathrm{r}=0.370, \mathrm{p}<0.01$, respectively). FPSs healthy control use was significantly correlated with fantasy $(r=0.304$, $\mathrm{p}<0.01)$ and social $(\mathrm{r}=0.302, \mathrm{p}<0.01)$ factors as the motives to play online games.

\section{Difference between the healthy control and risk group in the nine proposed DSM-5 diagnostic criteria}

The risk group showed higher frequency of endorsement of all nine DSM-5 diagnostic criteria compared to the healthy control group. The results are presented in Table 6 .

\section{Psychiatric symptoms \& impulsivity}

The BSI and BIS were used to assess the symptoms related to IGD. The mean scores of the risk group were noted to be significantly higher than those of healthy controls (Table 7). 'Obsession-compulsion', 'depression', and 'somatization' symptoms of the BSI were markedly higher in risk subjects than in the healthy control subjects, and the total BIS scores related to impulsivity were higher in the risk group as well.

\section{DISCUSSION}

This report presents the prevalence and symptoms of IGD as measured by an online survey of adults who engaged in recent Internet gaming. It was based on self-reported data on the criteria listed in the DSM-5. DSM-5 section III highlights the need for further investigation on IGD, and has proposed nine diagnostic criteria as suitable tools for IGD diagnosis. Applying the 5 cut-off point criteria as based on major preceding research ${ }^{2,10,11}$ and as suggested by the DSM-5, 13.8\% of all participants were categorized into the at-risk IGD group. Approximately $7.4 \%$ of adults aged $20-40$ years were deter-

Table 6. Positive responsive rate to DSM-5 Criteria $(\mathrm{N}=3041)$

\begin{tabular}{|c|c|c|c|c|}
\hline \multirow{2}{*}{$\begin{array}{c}\text { Variables } \\
\text { (\% within group) }\end{array}$} & \multicolumn{2}{|c|}{ DSM-5 diagnosis } & \multirow{2}{*}{$\chi^{2}$} & \multirow{2}{*}{$\mathrm{p}$} \\
\hline & Healthy control group $(\mathrm{N}=2622)$ & Risk group $(\mathrm{N}=419)$ & & \\
\hline Q4 & $444(16.9)$ & $356(85.0)$ & 862.461 & $<0.001$ \\
\hline Q6 & $246(9.4)$ & $342(81.6)$ & 1208.796 & $<0.001$ \\
\hline Q1 & $235(9.0)$ & $334(79.7)$ & 1188.960 & $<0.001$ \\
\hline Q8 & $465(17.7)$ & $330(78.8)$ & 696.776 & $<0.001$ \\
\hline Q5 & $263(10.0)$ & $319(76.1)$ & 1020.060 & $<0.001$ \\
\hline Q3 & $133(5.1)$ & $297(70.9)$ & 1288.782 & $<0.001$ \\
\hline Q2 & $127(4.8)$ & $274(65.4)$ & 1157.032 & $<0.001$ \\
\hline Q7 & $143(5.5)$ & $256(61.1)$ & 981.283 & $<0.001$ \\
\hline Q9 & $94(3.6)$ & $242(57.8)$ & 1078.695 & $<0.001$ \\
\hline
\end{tabular}

Q1: Preoccupation, Q2: Withdrawal, Q3: Tolerance, Q4: Unsuccessful attempts to control, Q5: Loss of other interests, Q6: Continued excessive use despite psychosocial problems, Q7: Deceiving regarding online gaming, Q8: Escape, Q9: Functional impairment. DSM-5: Diagnostic and Statistical Manual of Mental Disorders, Fifth Edition 
mined to be in the IGD risk group in our study, taking into account that $53.4 \%$ of this age group plays online games, as surveyed by the National Information Society Agency in Korea. ${ }^{30}$ In Germany, a study by Festl et al. ${ }^{15}$ showed a prevalence of $3.7 \%$ in adolescents and adults. In addition, Ferguson and colleagues reported the prevalence of IGD in the United States to be $3.1 \%$ in a meta-analysis of 33 published studies. ${ }^{17}$ In light of these data, the prevalence rate appears to be higher in Korea. In these studies, the disparity among the prevalence rates seems to be attributable to a number of factors, such as Internet environment, participants, diagnostic criteria, research methods, research period, and culture.

In this study, the difference in sociodemographic variables were not statistically significant between the healthy controls and the risk group. Therefore, sociodemographic variables do not appear to be significant factors in IGD diagnosis.

The risk group subjects tended to belong significantly more to the categories with a relatively high weekly online game playtime than healthy controls. However, in the risk group, almost all subjects belonged to the categories with a relatively low weekly online game playtime ( $<1$ hour: $22.7 \%$, $<4$ hour: $84.8 \%$ ). This is because DSM-5 criteria do not have the concept of exact game playtime. Our results are merely a clinical reference, and did not show the importance of game playtime in IGD, exactly. Therefore, we think that more detailed and systematic studies on the relationship between IGD and game playtime are needed.

In the assessment of motivations for online gaming, all factors measured in the MOGQ were significantly higher in the risk group; the primary motivations (those with the highest scores) for online gaming were 'escape' and 'coping. To our best knowledge, there has not been a comprehensive study on the IGD in adults based on MOGQ. One study ${ }^{31}$ of ado- lescents using the Internet Motive Questionnaire for Adolescents (IMG-A) demonstrated that 'coping' was a major motivation for online gaming use in subjects diagnosed with IGD. In addition, one study ${ }^{32}$ for pathological use of Internet games among Korean adolescents using the Internet Game Addiction (IGA) showed that 'escape' from self best explained the IGD. These results are in agreement with the data from this study.

Correlation analysis between online game types and the motives for online gaming revealed that there is a difference in the motives according to online game types between the risk group and healthy controls. In healthy controls, the motive for online game use strongly correlated with 'social' motivation regardless of the game type. On the other hand, the motives for online game use in risk individuals appeared to be different according to characteristics of each game type. These results suggest that risk subjects have more various motives for online game use than healthy controls, and have tendency to select game type by motives.

A positive response to the nine symptoms delineated in the DSM-5 diagnostic criteria of IGD was significantly higher in the risk group. This study found the DSM-5 criteria well identified the risk group.

The risk group scores were significantly higher in the factors of the BSI and BIS related to pathologic internet gaming use. The results show that the IGD risk group experienced more episodes of difficulty concentrating, loneliness, and insomnia. The risk subjects were also five times more likely to attempt suicide, be impulsive, and exhibit aggression than the healthy control group $(\mathrm{p}<0.001)$. These results are consistent with existing research ${ }^{3,33-36}$ on the relationship between psychiatric symptoms and disordered internet use which most studies have focused on thus far. Therefore comparison between our

Table 7. Brief Symptom Inventory and BIS scoring ( $N=3041)$

\begin{tabular}{|c|c|c|c|c|}
\hline \multirow{2}{*}{ Factors (mean $\pm S D$ ) } & \multicolumn{2}{|c|}{ DSM-5 level } & \multirow{2}{*}{$\mathrm{F}$} & \multirow{2}{*}{$\mathrm{p}$} \\
\hline & Healthy control group $(\mathrm{N}=2622)$ & Risk group $(\mathrm{N}=419)$ & & \\
\hline Somatization & $2.40 \pm 4.35$ & $10.08 \pm 7.11$ & 912.10 & $<0.001$ \\
\hline Obsession-compulsion & $3.55 \pm 4.52$ & $11.36 \pm 5.59$ & 1007.92 & $<0.001$ \\
\hline Interpersonal sensitivity & $1.99 \pm 3.05$ & $7.16 \pm 4.08$ & 941.26 & $<0.001$ \\
\hline Depression & $2.86 \pm 4.32$ & $10.89 \pm 5.94$ & 1109.13 & $<0.001$ \\
\hline Anxiety & $2.19 \pm 3.94$ & $9.73 \pm 6.08$ & 1106.07 & $<0.001$ \\
\hline Hostility & $2.05 \pm 3.26$ & $8.13 \pm 4.90$ & 1067.58 & $<0.001$ \\
\hline Phobic anxiety & $1.65 \pm 3.14$ & $7.63 \pm 5.04$ & 1073.07 & $<0.001$ \\
\hline Paranoid ideation & $2.08 \pm 3.30$ & $8.26 \pm 4.79$ & 1092.84 & $<0.001$ \\
\hline Psychoticism & $2.00 \pm 3.24$ & $8.06 \pm 4.75$ & 1093.35 & $<0.001$ \\
\hline BIS total & $38.56 \pm 8.74$ & $49.00 \pm 7.78$ & 530.135 & $<0.001$ \\
\hline
\end{tabular}

DSM-5: Diagnostic and Statistical Manual of Mental Disorders, Fifth Edition, BIS: Barratt Impulsiveness Scale 
results and those of previous research should be done with caution. Nonetheless, this research may serve as a basis for developing prevention strategies, education, and therapeutic interventions for IGD to include adult population.

There are some limitations of this study. First, the sample of our study may not be considered as representative of the Korean population as a whole. The results of our study are also limited in its generalizability to other countries. Second, the diagnostic criteria of IGD in DSM-5 used in this study were not standardized and were based upon self-reporting; therefore, we did not confirm the diagnostic criteria with clinical interview. In addition, all other survey tool including psychometric questionnaire was also based upon self-reporting. However, it is important to note that DSM- 5 diagnostic criteria were applied to a large number of adult individuals rather than children and adolescents. In addition, this study examined the various psychopathological aspects using scales and provided important baseline data and evidences supporting the suggestions for the IGD diagnostic criteria of the DSM-5. Future studies should attempt to overcome the limitations of this paper with respect to the sociodemographic background and environment of subjects and seek further validation of our results with clinical diagnostic interviews.

\section{Acknowledgments}

This work was supported by the Korean Health Technology R\&D project, Ministry of Health and Welfare (HI12 C0113). The funders had no role in study design, data collection and analysis, decision to publish, or preparation of the article.

This work was also supported by the Hungarian Scientific Research Fund (grant numbers: K83884 and K111938). Zsolt Demetrovics acknowledges financial support of the János Bolyai Research Fellowship awarded by the Hungarian Academy of Sciences.

\section{REFERENCES}

1. American Psychiatric Association. Diagnostic and Statistical Manual of Mental Disorders: DSM-5. Washington DC: American Psychiatric Association; 2013.

2. Petry NM, Rehbein F, Gentile DA, Lemmens JS, Rumpf HJ, Mößle T, et al. An international consensus for assessing internet gaming disorder using the new DSM-5 approach. Addiction 2014;109:1399-1406.

3. Oh EJ, Choi SW, Lee HK, Park JH, Ahn JH, Choi JE, et al. Relationship between internet game addiction and psychiatric symptoms in a child and adolescent psychiatric clinic. J Korean Acad Child Adolesc Psychiatry 2014;25:136-141.

4. Kweon YR, Kim SY. Predictors of protective factors for internet game addiction in middle school students using data mining decision tree analysis. J Korean Acad Psychiatr Ment Health Nurs 2014;23:12-20.

5. Lee JH. Structural Equation Modeling About the Domestic Violence Exposure on Adolescent's Internet Game Addiction: Focus on Parental Attachment as Mediator. Society for Social Work and Research 18th Annual Conference: Research for Social Change: Addressing Local and Global Challenges. SSWR, 2014.

6. Dowling NA, Quirk KL. Screening for internet dependence: do the proposed diagnostic criteria differentiate normal from dependent Internet use? Cyberpsychol Behav 2009;12:21-27.

7. Ahmadi J, Amiri A, Ghanizadeh A, Khademalhosseini M, Khademal- hosseini Z, Gholami Z, et al. Prevalence of addiction to the internet, computer games, DVD, and video and its relationship to anxiety and depression in a sample of Iranian high school students. Iran J Psychiatry Behav Sci 2014;8:75-80.

8. Pontes HM, Király O, Demetrovics Z, Griffiths MD. The conceptualisation and measurement of DSM-5 internet gaming disorder: the development of the IGD-20 test. PLoS One 2014;9:e110137.

9. Lee S, Yang S. Sy08-4psychological and cognitive aspects on internet gaming disorder. Alcohol Alcoholism 2014;49:i10-i10.

10. Petry NM, O'Brien CP. Internet gaming disorder and the DSM-5. Addiction 2013;108:1186-1187.

11. Ko CH, Yen JY, Chen SH, Wang PW, Chen CS, Yen CF. Evaluation of the diagnostic criteria of Internet gaming disorder in the DSM-5 among young adults in Taiwan. J Psychiatr Res 2014;53:103-110.

12. King DL, Delfabbro PH. Is preoccupation an oversimplification? A call to examine cognitive factors underlying internet gaming disorder. Addiction 2014;109:1566-1567.

13. Dowling NA. Issues raised by the DSM-5 internet gaming disorder classification and proposed diagnostic criteria. Addiction 2014;109: 1408-1409.

14. Cho H, Kwon M, Choi JH, Lee SK, Choi JS, Choi SW, et al. Development of the internet addiction scale based on the internet gaming disorder criteria suggested in DSM-5. Addict Behav 2014;39:1361-1366.

15. Festl R, Scharkow M, Quandt T. Problematic computer game use among adolescents, younger and older adults. Addiction 2013;108:592599.

16. Mentzoni RA, Brunborg GS, Molde H, Myrseth H, Skouverøe KJM, Hetland J, et al. Problematic video game use: estimated prevalence and associations with mental and physical health. Cyberpsychol Behav Soc Netw 2011;14:591-596.

17. Ferguson CJ, Coulson M, Barnett J. A meta-analysis of pathological gaming prevalence and comorbidity with mental health, academic and social problems. J Psychiatr Res 2011;45:1573-1578.

18. Choo H, Gentile DA, Sim T, Li D, Khoo A, Liau AK. Pathological videogaming among Singaporean youth. Ann Acad Med Singapore 2010; 39:822-829.

19. Tejeiro Salguero RA, Morán RMB. Measuring problem video game playing in adolescents. Addiction 2002;97:1601-1606.

20. Gentile D. Pathological video-game use among youth ages 8 to 18 : a national study. Psychol Sci 2009;20:594-602.

21. Nagygyörgy K, Urbán R, Farkas J, Griffiths MD, Zilahy D, Kökönyei G, et al. Typology and sociodemographic characteristics of massively multiplayer online game players. Int J Human Comp Interact 2013;29:192200.

22. Demetrovics Z, Urbán R, Nagygyörgy K, Farkas J, Zilahy D, Mervó B, et al. Why do you play? The development of the motives for online gaming questionnaire (MOGQ). Behav Res Methods 2011;43:814-825.

23. Derogatis LR, Spencer P. Brief Symptom Inventory: BSI. NJ: Pearson Upper Saddle River; 1993.

24. Derogatis LR, Melisaratos N. The brief symptom inventory: an introductory report. Psychol Med 1983;13:595-605.

25. Andreu Y, Galdón MJ, Dura E, Ferrando M, Murgui S, García A, et al. Psychometric properties of the Brief Symptoms Inventory-18 (BSI-18) in a Spanish sample of outpatients with psychiatric disorders. Psicothema 2008;20:844-850.

26. Mohammadkhani P, Dobson KS, Amiri M, Ghafari FH. Psychometric properties of the brief symptom inventory in a sample of recovered Iranian depressed patients. Int J Clin Health Psychol 2010;10:541-551.

27. Ryan C. British outpatient norms for the Brief Symptom Inventory. Psychol Psychother 2007;80:183-191.

28. Urbán R, Kun B, Farkas J, Paksi B, Kökönyei G, Unoka Z, et al. Bifactor structural model of symptom checklists: SCL-90-R and Brief Symptom Inventory (BSI) in a non-clinical community sample. Psychiatry Res 2014;216:146-154

29. Patton JH, Stanford MS, Barratt ES. Factor structure of the Barratt im- 
pulsiveness scale. J Clin Psychol 1995;51:768-774.

30. Ministry of Science, ICT and Future Planning. Internet addiction survey 2013. Gwacheon: National Information, Society Agency; 2013.

31. Bischof-Kastner C, Kuntsche E, Wolstein J. Identifying problematic internet users: development and validation of the Internet Motive Questionnaire for Adolescents (IMQ-A). J Med Internet Res 2014;16:e230.

32. Kwon JH, Chung CS, Lee J. The effects of escape from self and interpersonal relationship on the pathological use of internet games. Community Mental Health J 2011;47:113-121.

33. King DL, Delfabbro PH, Zwaans T, Kaptsis D. Clinical features and axis I comorbidity of Australian adolescent pathological Internet and video game users. Aust N Z J Psychiatry 2013;47:1058-1067.

34. Yen JY, Ko CH, Yen CF, Wu HY, Yang MJ. The comorbid psychiatric symptoms of Internet addiction: attention deficit and hyperactivity disorder (ADHD), depression, social phobia, and hostility. J Adolesc Health 2007;41:93-98.

35. Durkee T, Kaess M, Carli V, Parzer P, Wasserman C, Floderus B, et al. Prevalence of pathological internet use among adolescents in Europe: demographic and social factors. Addiction 2012;107:2210-2222.

36. Lam LT, Peng ZW. Effect of pathological use of the internet on adolescent mental health: a prospective study. Arch Pediatr Adolesc Med 2010;164:901-906 